\section{Estudo \\ Ecidebate}

em Testão

Plamejamento
Revista Estudo \& Debate, Lajeado, v. 27, n. 2, 2020. ISSN 1983-036X

DOI: http://dx.doi.org/10.22410/issn.1983-036X.v27i2a2020.2515

\title{
FATORES SOCIOINSTITUCIONAIS E TOLERÂNCIA À CORRUPÇÃO: UMA ANÁLISE APLICADA PARA INDIVÍDUOS ${ }^{1}$
}

\author{
Hilton Manoel Dias Ribeiro², Bruno de Souza Machado³
}

\begin{abstract}
Resumo: Houve um interesse crescente, nas últimas décadas, por estudos sobre as possíveis causas e consequências da corrupção, por meio de abordagens políticas, institucionais, sociais e econômicas. Dada a escassez de análises empíricas, o presente trabalho dedica-se a avaliar as relaçôes entre a tolerância à corrupção e as dimensões socioinstitucionais selecionadas, tais como gênero, educação, religiáo, confiança, categoria de renda, dentre outras. A World Values Survey (WVS) foi a fonte de dados utilizada, compreendendo o período de 1995 a 2014, conforme disponibilidade dos dados. Como métodos, empregou-se a Análise de Correspondência Múltipla, seguida do modelo de Regressão Logística Ordenada. Os resultados sugerem relaçóes significativas entre uma percepçáo mais tolerante à corrupção e aspectos como ser homem; ter preferências menos democráticas; ter menos confiança na impressa livre e ativa; ter menos confiança no sistema de justiça; estar em categorias mais elevadas de renda; ter preferência por menos igualdade de renda na sociedade; e ter menos escolaridade.
\end{abstract}

Palavras-chave: Corrupção. Valores. WVS. Análise Multivariada. Logit Ordenado.

\section{SOCIOINSTITUTIONAL FACTORS AND CORRUPTION TOLERANCE: AN APPLIED ANALYSIS FOR INDIVIDUALS}

\begin{abstract}
There has been a growing interest, in recent decades, in studies on the possible causes and consequences of corruption, through political, institutional, social and economic approaches. Given the scarcity of empirical analyzes, this paper is dedicated to assessing the relationship between corruption tolerance and the selected socio-institutional dimensions, such as gender, education, religion, trust, income category, among others. The World Values Survey (WVS) was the data source used, covering the period from 1995 to 2014, according to data availability. As methods, Multiple Correspondence Analysis was used, followed by the Ordered Logistic Regression model. The results suggest significant relationships between a more tolerant perception of corruption and aspects such as being a man; having less democratic preferences; have less confidence in the free and active press; having less confidence in the justice system; being in higher income categories; having a preference for less income equality in society; and have less schooling.
\end{abstract}

Keywords: Corruption. Values. WVS. Multivariate analysis. Ordered Logit.

1 Os autores agradecem à PROPP/UFJF pelo apoio.

2 Doutor em Economia. Professor no Dep. de Economia da Universidade Federal de Juiz de Fora - Campus GV. Coordenador do Econúcleo - Estudos Socioeconômicos.

3 Mestrando em Economia Aplicada na Universidade Federal de Viçosa - (DER/UFV). 


\section{Introdução}

Estudos a respeito das causas e consequências da corrupção se intensificaram na segunda metade do século XX, investigando os aspectos prejudiciais ao desenvolvimento das regióes, por afetar tanto a política, quanto a economia e a sociedade de forma geral (ROSE-ACKERMAN, 1978; MAURO, 1995; TANZI, 1998). As premissas que dão ao tema mais atenção por parte dos governos, políticos, pesquisadores são variadas e até mesmo divergentes, havendo campos de pesquisa de debate interdisciplinares, como a Ciência Política, a Sociologia, a Economia, a Ciência Jurídica, dentre outras.

A busca pela compreensão dos efeitos da corrupção tem permitido o surgimento de diversos estudos que visam analisar, por exemplo, a relação da corrupção com variáveis como o Produto Interno Bruto - PIB, o nível de investimento e os indicadores de governança. Todavia, os trabalhos empíricos que buscam compreender a corrupção em um nível micro, dos indivíduos, com o intuito de analisar empiricamente como estes agentes são tolerantes à corrupção, são relativamente mais escassos.

Segundo Filgueiras (2008), existe uma ligação íntima entre corrupção e moralidade, em que a corrupção é vista como um qualificativo da ordem política baseada em normas e valores. A corrupção não está limitada à Ciência Econômica, caracterizada pela perda monetária, uma vez que esse fenômeno assume um discurso complexo e flexível de acordo com as normas e valores previstos. Sendo assim, o presente trabalho busca avaliar as relaçóes entre fatores socioinstitucionais, tais como gênero, religião e confiança interpessoal e até mesmo categorias de renda, e a tolerância do indivíduo à corrupção.

Os dados utilizados são da World Values Survey - WVS (Pesquisa Mundial de Valores), compreendendo o período de 1995 a 2014, envolvendo 99 países e 306.406 indivíduos. A variável extraída da WVS e que serve de proxy para a medida de tolerência à corrupção se refere à percepção dos indivíduos sobre ser "justificável aceitar suborno no exercício de suas funçóes". No intuito de captar e analisar as relaçóes entre essa tolerência à corrupção e as demais variáveis, são empregados dois métodos. O primeiro refere-se à técnica multivariada da Análise de Correspondência Múltipla e o segundo lança mão do modelo de Regressáo Logística Ordenada.

Este trabalho segue a seguinte estruturação: além desta Introdução, a seção 2 traz uma discussão teórica e empírica, apresentando outras contribuições sobre o tema; a seção 3 refere-se à descrição da metodologia e da base de dados; a seção 4 aborda os resultados e discussóes; por fim, a seção 5 apresenta as consideraçóes finais.

\section{Aspectos teóricos e empíricos sobre corrupçáo}

O conceito de corrupção é múltiplo, agregando a si definiçóes que se encaixam a cada situação em que é requisitado. Para Filgueiras (2008: 144-145), "há no mundo contemporâneo um contexto de crise que se expressa no discurso político, com o objetivo de atestar as mudanças e expor as mazelas sociais e políticas”. Para o autor, mesmo com a democracia se expandindo pelo mundo, nas últimas décadas, a corrupção se tornou uma prática cada vez mais normal para os agentes. Tendo a corrupção uma importância 
considerável, como não poder defini-la? A palavra corrupção vem do latim corruptus. Conforme Silva (1996: 2), ela:

[...] denota decomposição, putrefação, depravação, desmoralização, sedução e suborno. Normalmente associamos corrupção a um ato ilegal, onde dois agentes, um corrupto e um corruptor, travam uma relação "fora-da-lei", envolvendo a obtençáo de propinas. O senso comum identifica a corrupçáo como um fenômeno associado a poder, aos políticos e às elites econômicas. Mas igualmente considera a corrupçáo algo frequente entre servidores públicos (como policiais e fiscais, por exemplo) que usam o "pequeno poder" que possuem para extorquir renda daqueles que teoricamente corrompem a lei (ultrapassando o sinal vermelho ou não pagando impostos)

De acordo com o Banco Mundial (1997), o fenômeno pode ser definido como o abuso do poder público para benefício privado. Entretanto, tal definição é por vezes questionada pelo fato da não incorporação da corrupção no meio privado. Para Mauro (1996), a corrupção é vista como o abuso da função do cargo público para ganhos privados, principalmente em áreas que se pode apropriar um alto nível de renda (lucro excessivo). Já a definiçẫo de Heidenheimer (1989: 6) considera a corrupção como uma "transação entre atores do setor público e privado através da qual bens coletivos são ilegitimamente convertidos em payoffs privados".

Filgueiras (2008) busca traçar a história do conceito de corrupção, desde a antiguidade até a era contemporânea. $\mathrm{O}$ autor procura evidenciar as diferentes formas que tal fenômeno foi estudado e posto em prática ao longo do tempo. Mesmo evidenciado um enfoque relativamente mais político, o autor levanta diversos pontos a respeito da corrupção, perpassando por diferentes áreas. Seu trabalho, ao demonstrar a relação íntima entre a corrupçáo e a moralidade, realiza a divisão desta última em juízos de valor e juízos de necessidade, abarcando as formas de corrupção no seu âmbito político, cultural, social e econômico.

Desse modo, para este último autor, dada a presente escolha por uma medida de tolerância à corrupção que envolve a percepção de aceitaçáo da prática de suborno por parte dos indivíduos, identificam-se aqui duas dimensões da corrupção. A primeira, mais evidente, refere-se à forma econômica, a partir da consideraçáo do juízo em contexto de fraude e da substância do ato como apropriação indevida de algo do domínio comum; a segunda está relacionada à forma cultural, a partir do juízo em contexto de desonestidade e da substância do ato como campo simbólico.

Johnston (1982) define corrupção por meio de três perspectivas: a primeira trata de explanaçóes personalísticas, em que a corrupção é vista como "más ações de gente ruim", como vindas do povo, da fragilidade da natureza humana. Seu foco está na investigaçáo psicológica ou na ganância e racionalizaçâo humanas como causas da corrupção; a segunda trata de explanações institucionais, em que a corrupção decorre de problemas de administração, que podem ser de pelo menos dois tipos - o decorrente de estímulo exercido por líderes corruptos que levam a corrupção a se reproduzir intra e interinstitucionalmente e o advindo dos "gargalos" criados por leis e regulamentos que trazem rigidez à burocracia; e a terceira aborda as explanaçôes sistêmicas, na qual a corrupçáo emerge da interação do 
governo com o público constituindo parte integrante do sistema político como uma entre as várias formas de influência.

A corrupção passou a ter mais atenção no cenário mundial após a década de 1990. Para Tanzi (1998: 559) "[...] por que tanta atenção agora? É porque há mais corrupção do que no passado? Ou é porque mais atenção está sendo dada a um fenômeno que sempre existiu, mas que foi em grande parte, embora não completamente, ignorado?”. Para o autor, a resposta não é óbvia e não há estatísticas confiáveis que a torne definitiva. $\mathrm{Na}$ tentativa de compreender melhor tais questionamentos, ele destaca motivos que corroboram para essa mudança de postura após a década de 1990. Primeiro, o fim da Guerra Fria, período no qual se ignorava uma forte presença da corrupção na política nacional e entre diversos países; segundo, o crescente número de governos sob um regime democrático; terceiro, os meios de comunicação mais ativos e livres, a exemplo da imprensa; e quarto, o advento de organizações não governamentais na criação de movimentos anticorrupção são alguns dos motivos que levaram a uma maior atenção à corrupção a partir de $1990^{4}$.

Alguns autores - Mauro (1995); De La Croix e Delavallad (2007) - consideram que a corrupção é excessiva nos países em desenvolvimento, onde o clientelismo e a fragilidade institucional são as normas, enquanto os países desenvolvidos são menos corruptos pela adoção de práticas de tolerância zero à corrupção, por fazer justiça relativamente mais igual para todos os cidadãos. Essa ligação entre corrupção e renda é a base dessa discussão e está inserida no presente trabalho. Considerando todos os níveis de funcionários do governo e o setor privado, quase nada pode ser excluído desse fenômeno social.

Para Goel e Nelson (2007), o governo em alguns países em desenvolvimento parece menos severo na luta contra a corrupção, criando uma nova percepção por parte dos indivíduos de que é menos rigorosa a punição por prática de suborno e a transferência ilegal de recursos para países vizinhos. Os autores argumentam que potenciais agentes envolvidos em suborno podem se tornar mais ousados e se engajar em atos corruptos quando observam outros também se engajando em atividades semelhantes.

Porém, é importante retornar à década de 1960, período em que atos corruptos, como o pagamento de subornos de empresas privadas aos funcionários do setor público eram vistos como benéficos para o desenvolvimento da economia, uma vez que se desviavam da burocracia do setor público e permitiam uma melhora da eficiência econômica (LEFF, 1964; HUNTINGTON, 1968). Porém, no final da década seguinte, uma nova visão emergia com Rose-Arckerman (1978). A autora discute sobre a burocracia governamental, a relação do funcionalismo público com o setor privado e o surgimento da corrupção nessa relação, como também as consequências da corrupçáo no que tange a democracia e a economia.

A corrupção pode estar presente em diferentes casos, de forma isolada, tanto dentro do setor público quanto do setor privado, mas o contato entre tais setores não pode ser posto de lado. Hodgson e Jiang (2007) trazem uma crítica às pesquisas sobre corrupção, as

4 Outros motivos que colaboraram para o aumento dessa atenção foram o surgimento da globalização, uma maior preocupação do mercado com as distorçôes que a corrupçáo causa e a influência dos Estados Unidos em diversas instituiçôes internacionais (TANZI, 1998). 
quais enfatizam o setor público predominantemente. Os autores argumentam que uma vez sendo contagiosa, a corrupção não respeita os limites setoriais entre o que é setor público e o que é setor privado.

A partir dessa discussão teórica, uma apresentação sobre as medidas de corrupção torna-se complementar. Para Abramo (2005), se a corrupção é um assunto importante no terreno econômico, então medi-la se torna uma atividade necessária. Tanzi (1998), por sua vez, argumenta que se a corrupção pudesse ser medida, poderia ser eliminada. Pelos estudos realizados até hoje ainda não é possível medi-la de forma exata e objetiva. Para contornar esse obstáculo, organizaçóes tentam mensurá-la de forma indireta. Nesta tentativa, uma delas, que vem se destacando mundialmente, é a Transparência Internacional (TI), uma organização não governamental que lança anualmente, desde 1995, o Índice de Percepçôes de Corrupção (do inglês, Corruption Perception Index - CPI) 5 .

Barbosa (2012), além de mencionar o CPI, o autor cita outros indicadores para fins de comparação, na intenção de demonstrar a confiabilidade do primeiro. Ele destaca a base de dados da WVS (World Values Survey), a partir das perguntas "Em sua opinião, quâo disseminada em seu país é a prática de suborno e da corrupção?" e "Você acha que a maioria das pessoas levaria vantagem em cima de você se tivesse a chance, ou tentaria ser justa?" $\mathrm{O}$ autor ainda cita o Barômetro da Corrupção Global, o Índice de Pagadores de Propina e o Índice KKM - Kaufmann, Kraay and Mastruzzi (2009).

Já Donchev e Ujhelyi (2009) também mencionam o CPI, da Transparência Internacional; o Índice de Controle de Corrupção, do Banco Mundial; e o Índice do Guia Internacional de Risco País, discutindo qual caminho esses índices têm tomado para medir a corrupção. Os autores destacam que tais índices são classificados normalmente como medidas de experiência de corrupção e, a partir disso, questionam como estas preveem medidas de percepção e tolerância à corrupção. Eles também reforçam que estudos envolvendo a tolerância à corrupção são uma parte importante para compreensão da atitude das pessoas em relação aos sistemas e à confiança nas instituições, o que pode afetar outras dimensóes socioeconômicas. Por fim, os autores levantam a necessidade de se entender quais políticas são mais eficazes para alterar as percepções do nível de corrupção de um país e qual é o impacto em variáveis reais.

No nível dos países, em particular, fatores como religião, desenvolvimento econômico e instituições democráticas, sistematicamente, enviesam a percepção e tolerância à corrupção para longe da experiência de corrupção, de acordo com estes últimos autores. No nível dos indivíduos, os resultados vão ao encontro dos resultados obtidos para o nível macro. Além disso, os resultados mostram que várias características individuais, como educação, idade, renda e situação de emprego afetam a tolerância à corrupção. Barbosa (2012) compreende que os índices de percepção de corrupção são importantes para se analisar o fenômeno. $\mathrm{O}$ autor busca formas de demonstrar como estes indicadores podem ser instrumentos úteis

5 O índice é feito por meio da construção de um ranking onde a TI emprega um nível de corrupção para os países, variando de 0 a 10 . Quanto mais próximo de 10, menos corrupto é o país; e quanto mais próximo de 0, mais corrupto tende a ser o país. Para mais informaçóes acessar: <http:transparênciainternacional.org>. 
na compreensão das formas de combate, a partir da discussão sobre seu caráter cultural, político, social e institucional.

Compreender os determinantes e efeitos da corrupção é tarefa difícil. Contudo, avaliar os fatores que afetam a tolerância à corrupção pode ser um exercício importante neste campo. Segundo o argumento de Lambsdorff (2006: 4), há uma complexidade em perceber "[...] se a corrupção causa outras variáveis ou é ela própria a consequência de certas características". Neste sentido, o autor argumenta que não se devem tirar conclusôes inflexíveis quanto às causalidades da corrupção.

Shabbir e Anwar (2007) dividem as causas da corrupção em econômicas e não econômicas. As causas econômicas englobam, por exemplo, liberdade econômica, integração internacional (ligado à globalização) e distribuição de renda, enquanto as causas não econômicas seriam os fatores sociopolíticos, determinantes religiosos, liberdade $\mathrm{da}$ imprensa e outros aspectos institucionais. Já Garcia (2003) elenca as causas da corrupção analisando o nível que se encontra o desenvolvimento político e institucional, a excessiva intervenção estatal na economia, a alocação política dos recursos, o poder discricionário dos agentes públicos, a liberdade de imprensa e a fraqueza das instituiçóes públicas.

Para Tanzi (1998), a corrupção é mais presente em países com histórico mais recente de instalação da democracia, onde as instituições não são muito estáveis, característica encontrada em países em desenvolvimento. Por outro lado, Ades e Di Tella (1996) acreditam que a corrupção está ligada à falta de concorrência no mercado interno, sugerindo que uma abertura comercial mais eficaz poderia diminuir a corrupção nessa área. Para Lambsdorff (2006), a baixa concorrência entre as empresas privadas contribui para o aumento dos níveis de corrupção. Assim, as pesquisas sugerem que países com maiores escores de liberdade econômica estão associados a níveis mais baixos de corrupção (PARK 2003; ORTEGA et al. 2011).

Os trabalhos de Power e González (2003) e Barbosa (2012), sob outra perspectiva, já relatam as causas culturais da corrupção, argumentando sobre os valores culturais que a literatura tem associado com a prática de atos corruptos. Os primeiros discutem a associação entre gênero, confiança interpessoal, tradiçóes religiosas e corrupção. Já Barbosa (2012) divide as causas culturais da corrupção em três grupos, a saber: confiança interpessoal e relacional entre os indivíduos; tradiçóes religiosas, como vistas por Power e González (2003); e a questão de gênero.

Este último autor fez uso da base de dados da World Values Survey (WVS) para a realização de uma pesquisa comparada transnacional com a intenção de testar a existência de correlaçóes e influências entre os valores sociais compartilhados e a corrupção. Entretanto, Barbosa (2012) reconhece que uma parte considerável das pesquisas rejeita esse tratamento culturalista ${ }^{6}$ das causas da corrupção, optando por fatores econômicos, políticos

6 Barbosa (2012) destaca que algumas das causas de corrupção, que a literatura classifica como institucionais, se confundem com as causas culturais, como as tradiçôes religiosas. Para Power e González (2003), a abordagem culturalista, quando se tratando de cultura e capital social, deve sim ter um papel mais ativo nas pesquisas sobre democracia e desenvolvimento. 
e institucionais. Ele destaca que a maioria dos trabalhos da literatura sobre as causas da corrupção buscam explicaçóes econômicas ou políticas.

Outras causas socioinstitucionais são destacadas por Barbosa (2012), com ênfase na relação entre desenvolvimento, renda e corrupçáo, e na associação desta com questóes como liberdades política e de expressão. Segundo o autor, os regimes mais abertos, livres e participativos são marcados por uma maior transparência. "A imprensa é livre para investigar e denunciar o governo, a sociedade tem mais meios de pressão e a oposição pode atuar de forma ampla, 'vigiando’ o governo” (BARBOSA, 2012: 55).

Para Power e González (2003), a relação entre gênero e corrupção tem sido analisada de diferentes modos. A ocupação social de homens e mulheres, principalmente em cargos públicos e determinadas profissóes podem se mostrar bem distinta. De qualquer modo, para os autores, o impacto do gênero sobre a corrupçáo é passível de análise.

Swamy et al. (1999) também analisaram a relação entre gênero e corrupção. Os autores buscaram evidências tanto no nível macro quanto no nível micro. No nível micro, uma das bases de dados utilizada foi a WVS. A pergunta de maior interesse para os autores foi a respeito de ser ou não "justificável aceitar suborno no exercício de suas funções”, também selecionada para a presente pesquisa. Os resultados indicaram que na percepção das mulheres, estas são menos propensas a tolerar a corrupção do que os homens, neste caso, aceitar o pagamento de suborno. Conclusão semelhante está exposta em Dollar et al. (2001).

No que se refere às tradiçóes religiosas, como a protestante, a católica, a muçulmana e a ortodoxa oriental, estas são frequentemente lembradas ao se estudar corrupção devido ao grau de influência que podem exercer sobre a tolerância à corrupção. As três últimas, por terem uma organizaçâo em um nível mais hierarquizado, comumente são atreladas a maiores níveis de corrupção (LA PORTA et al., 1997). Na visão de Power e González (2003), ambientes onde as religiōes mais hierarquizadas, como a católica, a muçulmana e a ortodoxa oriental estão presentes, são mais afetados por uma tendência de queda dos questionamentos das autoridades públicas do que nos ambientes com atuação das tradiçóes protestantes, a princípio, menos hierarquizadas.

Segundo os resultados do estudo de La Porta et al. (1999), países com a presença católica e muçulmana estão associados a um mal desempenho do governo, que implica em uma ocorrência maior de casos de corrupção. Treisman (2000) destaca o fato de que os ambientes onde as tradiçóes protestantes se fazem presentes e há uma separação mais nítida entre igreja e Estado, favorece o surgimento de uma sociedade civil mais forte e independente, capaz de monitorar as açóes do Estado de forma mais eficaz.

Apesar do foco deste estudo não se apoiar nos efeitos da corrupção, vale destacar alguns argumentos presentes na literatura. Tanto Leff (1964) quanto Huntington (1968) argumentaram que a eficiência econômica se elevaria com a ajuda da corrupção agindo como uma válvula de escape em meio à tamanha burocracia. Leff (1964: 11) indica que "a corrupção também pode ajudar o desenvolvimento econômico, possibilitando uma maior taxa de investimento". Para Huntington (1968), a corrupção é fruto da modernização dos países e, diante do aumento do nível de burocratização, a corrupção seria uma saída 
para o crescimento. Todavia, Lambsdorff (2006) afirma que uma maneira de contestar tais argumentos favoráveis à corrupção é perceber seu impacto na qualidade das instituiçóes públicas.

\section{Metodologia e base de dados}

A partir do objetivo delineado, qualseja, avaliar a relação entrefatoressocioinstitucionais e a tolerância à corrupção, dois métodos são propostos. O primeiro contempla a Análise de Correspondência Múltipla, capaz de identificar as primeiras associaçóes entre o conjunto de variáveis selecionadas; e o segundo, via modelo de Regressão Logística Ordenada, propóe uma análise dos possíveis efeitos de um conjunto de valores e características individuais sobre a proxy que avalia a tolerância à corrupção.

\subsection{Base de dados}

A World Values Survey Association (WVSA) é a responsável pela elaboração da Pesquisa Mundial de Valores (WVS) e contempla um conjunto significativo de países. A pesquisa se concentra nas crenças e valores dos indivíduos e os impactos dessas variáveis na sociedade, na política e na economia. A associaçáo disponibiliza um banco de dados no formato longitudinal, compreendendo as "ondas" de entrevistas que vão de 1981 até 2014. Após a análise do número de observaçóes de cada onda, optou-se pelo uso daquelas com maior volume de observaçóes. A Tabela 1 apresenta as ondas da WVS como também o número de observaçóes e a participação percentual de cada uma na composição total. Assim, o período utilizado na pesquisa vai de 1995 a 2014, contemplando 99 países e 306.406 indivíduos. Adota-se o recorte por ondas seguindo a mesma constituição do banco de dados da WVS. A relação de países pode ser vista na Tabela A1 dos Anexos.

Tabela 1 - Ondas da WVS

\begin{tabular}{c|c|c|c|c}
\hline Onda & Período & Frequência & $\%$ & $\%$ Acum. \\
\hline 3 & $1995-1998$ & 77.129 & 25,17 & 25,17 \\
\hline 4 & $1999-2004$ & 59.030 & 19,27 & 44,44 \\
\hline 5 & $2005-2009$ & 83.975 & 27,40 & 71,84 \\
\hline 6 & $2010-2014$ & 86.272 & 28,16 & 100 \\
\hline Total & - & 306.406 & 100 & - \\
\hline
\end{tabular}

Fonte: Elaboração própria a partir da WVS.

A proxy para a medida de tolerância à corrupção é construída a partir da pergunta: "É justificável aceitar suborno no exercício de suas funçôes?” Power e González (2003: 56), que utilizaram a base de dados para o período de 1995 a 1997, consideraram essa variável como “[...] a melhor pergunta existente nas pesquisas sobre percepçôes globais de corrupção". A resposta para essa pergunta varia de 1 até 10 , em que 1 indica "Nunca justificável" e 10 "Sempre justificável". Para a análise multivariada, essa variável foi modificada, agrupando-se as categorias em quatro, a saber: "baixo" (1 e 2); "Baixo-médio" (3, 4 e 5), "Médio-alto" (6, 
7 e 8) e alto (9 e 10), para facilitar a análise visual dos gráficos; já para a análise de regressão logística ordenada, a variável foi mantida com suas dez categorias.

A Tabela 2 apresenta uma descrição estatística dessa variável de interesse. Quando se observa a variável com 10 (dez) categorias, destaca-se que $70 \%$ dos indivíduos consideram nunca ser justificável aceitar suborno no exercício de suas funçōes, enquanto $4 \%$ desses indivíduos percebem como sempre justificável aceitar suborno, aproximadamente. Sobre a variável de interesse adaptada (quatro categorias), cabe destacar que cerca de $78 \%$ dos entrevistados se enquadram em um nível "baixo", dentro da percepçấo de nunca ser justificável aceitar suborno; $11 \%$ em um nível "baixo-médio"; 3\%, estão inseridos em um nível "médio-alto"; e 1,91\% em um nível "alto".

Tabela 2 - Descrição da variável dependente

\begin{tabular}{|c|c|c|c|c|c|}
\hline Tipo de análise a ser empregada & Código & Categoria & Freq. & $\%$ & $\%$ Acum. \\
\hline \multirow{6}{*}{$\begin{array}{c}\text { Análise de Correspondência } \\
\text { Múltipla (ACM) }\end{array}$} & \multirow{5}{*}{ Corrup* } & Baixo & 240.946 & 78,64 & 78,64 \\
\hline & & Baixo-médio & 33.993 & 11,09 & 89,73 \\
\hline & & Médio-alto & 11.055 & 3,61 & 93,34 \\
\hline & & Alto & 5.865 & 1,91 & 95,25 \\
\hline & & missing & 14.547 & 4,75 & 100 \\
\hline & & Total & 306.406 & 100 & - \\
\hline \multirow{12}{*}{$\begin{array}{c}\text { Regressão Logística } \\
\text { Ordenada (LOGIT Ordenado) }\end{array}$} & \multirow{12}{*}{ Corrup_ } & 1 & 213.523 & 69,69 & 69,69 \\
\hline & & 2 & 27.423 & 8,95 & 78,64 \\
\hline & & 3 & 15.246 & 4,97 & 83,61 \\
\hline & & 4 & 8.559 & 2,79 & 86,40 \\
\hline & & 5 & 10.188 & 3,33 & 89,73 \\
\hline & & 6 & 4.864 & 1,59 & 91,32 \\
\hline & & 7 & 3.310 & 1,08 & 92,40 \\
\hline & & 8 & 2.881 & 0,94 & 93,34 \\
\hline & & 9 & 1.832 & 0,60 & 93,94 \\
\hline & & 10 & 4.033 & 1,31 & 95,25 \\
\hline & & missing & 14.547 & 4,75 & 100 \\
\hline & & Total & 306.406 & 100 & - \\
\hline
\end{tabular}

Nota: O conjunto de respostas como 'Não sei', 'Sem resposta', 'Não aplicado', 'Não respondido na pesquisa' e 'Missing; Desconhecido', foram consideradas como missing.

Fonte: Elaboração própria a partir da WVS.

As variáveis explicativas escolhidas estão alinhadas à discussão teórica, envolvendo dimensóes como gênero, escolaridade, renda, confiança e religião. A escolha dessas variáveis se deu a partir da disponibilidade de dados da WVS. Uma descrição das variáveis e uma estatística descritiva das mesmas podem ser vistas nas Tabelas 3 e 4, respectivamente. Essas variáveis são categóricas, sendo a maioria do tipo binária (dummy). Uma análise de correlaçáo simples pode ser visualizada na Tabela A2 dos Anexos. 
Tabela 3 - Descrição das variáveis explicativas

\begin{tabular}{l|l|c}
\hline Variáveis & \multicolumn{1}{|c|}{ Descrição } & Freq. \\
\hline Gênero & Assume valor 1 para homem. & 306.113 \\
\hline Educ & Nível educacional. Assume valor 1 para alto (Ensino Superior ou acima). & 285.170 \\
\hline Trab & Situaçáo de emprego. Assume valor 1 para empregado. & 297.598 \\
\hline Renda & Nível de renda. Assume valor 1 para alto. & 280.121 \\
\hline Rend_iguais & As rendas devem ser mais iguais. Assume valor 1 para não. & 291.712 \\
\hline Rend_prop & As pessoas devem ser responsáveis pelo seu sustento. Assume 1 para não. & 293.046 \\
\hline Democ & A democracia é boa como sistema político. Assume valor 1 para não. & 273.289 \\
\hline Conf_interp & A maioria das pessoas pode ser confiável. Assume valor 1 para sim. & 292.725 \\
\hline Conf_impr & Confiança na imprensa. Assume valor 1 para não. & 285.240 \\
\hline Conf_gov & Confiança no governo. Assume valor 1 para náo. & 279.431 \\
\hline Conf_just & Confiança no sistema de justiça. Assume valor 1 para não. & 227.939 \\
\hline Conf_igrej & Confiança nas igrejas. Assume valor 1 para náo. & 286.178 \\
\hline Relig & $\begin{array}{l}\text { Denominaçóes religiosas. Assume valor 1 para protestante, 2 para católica, } \\
\text { 3 para muçulmana, 4 para ortodoxa, 5 para outra, e 6 para nenhuma. }\end{array}$ & 294.583 \\
\hline
\end{tabular}

Fonte: Elaboração própria a partir da WVS.

Tabela 4 - Estatística descritiva para variáveis explicativas

\begin{tabular}{|c|c|c|c|c|c|c|c|}
\hline \multicolumn{4}{|c|}{ Gênero } & \multicolumn{4}{|c|}{ Educ } \\
\hline Categoria & Freq. & $\%$ & $\%$ Acum. & Categoria & Freq. & $\%$ & $\%$ Acum. \\
\hline Homem & 147.438 & 48,12 & 48,12 & Alto & 68.526 & 22,36 & 22,36 \\
\hline Mulher & 158.675 & 51,78 & 99,90 & Baixo & 216.644 & 70,71 & 93,07 \\
\hline missing & 293 & 0,10 & 100 & missing & 21.236 & 6,93 & 100 \\
\hline Total & 306.406 & 100 & - & \begin{tabular}{|l} 
Total \\
\end{tabular} & 306.406 & 100 & - \\
\hline \multicolumn{4}{|c|}{ Trab } & \multicolumn{4}{|c|}{ Renda } \\
\hline Categoria & Freq. & $\%$ & \% Acum. & Categoria & Freq. & $\%$ & $\%$ Acum. \\
\hline Empregado & 158.851 & 51,84 & 51,84 & Alto & 96.215 & 31,40 & 31,40 \\
\hline Desempregado & 138.747 & 45,28 & 97,12 & Baixo & 183.906 & 60,02 & 91,42 \\
\hline missing & 8.808 & 2,88 & 100 & missing & 26.285 & 8,58 & 100 \\
\hline Total & 306.406 & 100 & - & Total & 306.406 & 100 & - \\
\hline \multicolumn{4}{|c|}{ Rend_iguais } & \multicolumn{4}{|c|}{ Rend_prop } \\
\hline Categoria & Freq. & $\%$ & $\%$ Acum. & Categoria & Freq. & $\%$ & $\%$ Acum. \\
\hline Sim & 135.764 & 44,31 & 44,31 & Sim & 107.311 & 35,02 & 35,02 \\
\hline Não & 155.948 & 50,89 & 95,20 & Não & 185.735 & 60,62 & 95,64 \\
\hline missing & 14.694 & 4,80 & 100 & missing & 13.360 & 4,36 & 100 \\
\hline Total & 306.406 & 100 & - & Total & 306.406 & 100 & - \\
\hline \multicolumn{4}{|c|}{ Conf_interp } & \multicolumn{4}{|c|}{ Conf_impr } \\
\hline Categoria & Freq. & $\%$ & $\%$ Acum. & Categoria & Freq. & $\%$ & $\%$ Acum. \\
\hline Sim & 76.031 & 24,81 & 24,81 & Sim & 128.493 & 41,93 & 41,93 \\
\hline Não & 216.694 & 70,72 & 95,53 & Não & 156.747 & 51,16 & 93,09 \\
\hline missing & 13.681 & 4,47 & 100 & missing & 21.166 & 6,91 & 100 \\
\hline
\end{tabular}




\begin{tabular}{|c|c|c|c|c|c|c|c|}
\hline Total & 306.406 & 100 & - & Total & 306.406 & 100 & - \\
\hline \multicolumn{4}{|c|}{ Conf_gov } & \multicolumn{4}{|c|}{ Conf_just } \\
\hline Categoria & Freq. & $\%$ & $\%$ Acum. & Categoria & Freq. & $\%$ & $\%$ Acum. \\
\hline Sim & 131.064 & 42,78 & 42,78 & Sim & 107.891 & 35,21 & 35,21 \\
\hline Não & 148.367 & 48.42 & 91,20 & Não & 120.048 & 39,18 & 74,39 \\
\hline missing & 26.975 & 8,80 & 100 & missing & 78.467 & 25,61 & 100 \\
\hline Total & 306.406 & 100 & - & Total & 306.406 & 100 & - \\
\hline \multicolumn{4}{|c|}{ Relig } & \multicolumn{4}{|c|}{ Conf_igrej } \\
\hline Categoria & Freq. & $\%$ & \% Acum. & Categoria & Freq. & $\%$ & $\%$ Acum. \\
\hline Protestante & 38.544 & 12,58 & 12,58 & Sim & 191.744 & 62,58 & 62,58 \\
\hline Católica & 68.119 & 22,23 & 34,81 & Não & 94.434 & 30,82 & 93,40 \\
\hline Muçulmana & 62.087 & 20,26 & 55,07 & missing & 20.228 & 6,60 & 100 \\
\hline Ortodoxa & 31.472 & 10,27 & 65,34 & Total & 306.406 & 100 & - \\
\hline Outra & 42.611 & 13,90 & 79,24 & \multicolumn{4}{|c|}{ Democ } \\
\hline Nenhuma & 51.750 & 16,90 & 96,14 & Categoria & Freq. & $\%$ & $\%$ Acum. \\
\hline missing & 11.823 & 3,86 & 100 & Sim & 244.668 & 79,85 & 79,85 \\
\hline \multirow[t]{3}{*}{ Total } & 306.406 & 100 & - & Não & 28.621 & 9,34 & 89,19 \\
\hline & & & & missing & 33.117 & 10,81 & 100 \\
\hline & & & & Total & 306.406 & 100 & - \\
\hline
\end{tabular}

Fonte: Elaboração própria a partir da WVS.

Sobre a Tabela 4, do total de entrevistados (306.406), 48\% são homens, enquanto $51 \%$ são mulheres; $70 \%$ se enquadram no nível baixo de escolaridade; $60 \% \mathrm{em}$ um nível baixo de renda; e 45\% são considerados desempregados no momento da entrevista. Quanto à confiança, somente $24 \%$ acreditam que a maioria das pessoas pode ser confiável; $51 \%$ se mostraram não confiantes ao se falar da imprensa, enquanto $42 \%$ e $35 \%$ indicaram confiar no governo e no sistema de justiça, respectivamente. No tocante à democracia, $79 \%$ concordam que ela é um bom sistema político. A respeito das tradiçóes religiosas, $12 \%$ se intitularam como protestantes, $22 \%$ como católicos e $20 \%$ como muçulmanos, porém, $16 \%$ disseram não seguir nenhuma religião.

\subsection{Análise de Correspondência Múltipla - ACM}

A ACM envolve uma análise multivariada de dados do tipo categórico (GOWER, 1990; GOWERE HAND, 1996; GREENACRE, 2006). Este método de análise multivariada é adequado para pesquisas que envolvem um conjunto de variáveis categóricas. Para Souza, Bastos e Vieira (2010), a análise de correspondência permite visualizar graficamente as relaçóes entre as diferentes categorias. Fávero e Belfiore (2015) ressaltam que antes da realização da análise de correspondência múltipla, somente variáveis que demonstraram possuir certa associação com a variável de interesse, após aplicação do teste Qui-quadrado $\left(X^{2}\right)$, permanecem na análise. Assim, os autores recomendam a realização de um teste $X^{2}$ para cada par de variáveis selecionadas. 
Seja um banco de dados formado por $N$ observaçóes e $Q$ variáveis, com $Q$ maior que 2. Tem-se que cada variável $q$, variando de 1 a $Q$, possua $I_{q}$ categorias. O número total de categorias segue (1):

$$
J=\sum_{q=1}^{Q} J_{q}
$$

A partir dessas informaçóes, é possível estabelecer uma tabela de contingência $X_{0}$ que apresenta relaçóes entre suas linhas e colunas, demonstrando como as variáveis estão associadas. Para Fávero e Belfiore (2015), é possível gerar um novo banco de dados, elaborado a partir dessa tabela de contingência e formado somente por variáveis binárias a partir da codificação das categorias de cada variável para cada observação. Essa codificação, segundo os autores, dá origem a matriz binária $Z$, pela qual se define a inércia principal total da ACM.

Por fim, a partir dos autovalores e autovetores determinados por meio da matriz $\mathrm{Z}$ criada, as coordenadas de cada uma das categorias de cada variável inserida na análise de correspondência múltipla podem ser definidas e o mapa perceptual será gerado. Coordenadas-padrão são os nomes dados às coordenadas geradas pela matriz Z. Esses mapas (gráficos) são diagramas de dispersão que representam as categorias das variáveis na forma de pontos em relação a eixos de coordenadas ortogonais. Um mapa perceptual pode ser construído por $\mathrm{N}$ dimensóes, embora a apareça somente as duas primeiras dimensóes com maior inércia parcial total (FÁVERO E BELFIORE, 2015).

É importante destacar que quanto maior o número de variáveis estiver na análise de correspondência múltipla, maior será o número de categorias, ocasionando um maior número de dimensóes e consequentemente aumentando o número de inércias principais parciais. Para facilitar a análise gráfica, optou-se aqui por separar as variáveis em 4 (quatro) dimensóes, a saber: características demográficas, religião, renda e confiança.

\subsection{LOGIT Ordenado}

O interesse por de trás de regressóes logísticas está na avaliação da probabilidade $p$ de ocorrer determinado evento baseado no comportamento das variáveis explicativas que compóem o modelo. Este tipo de modelo ordenado foi proposto inicialmente por Aitchison e Silvey (1957) para analisar experimentos nos quais a resposta dos sujeitos a vários níveis de estímulos era dividida em classes ordenadas. As categorias de uma determinada variável podem ser colocadas em uma ordem de classificaçáo, mas as distâncias entre suas categorias não podem ser observadas (CAMERON AND TRIVEDI, 2005; LONG E FREESE, 2006).

O modelo Logit ordenado é comumente apresentado por meio de uma variável latente $y *$, variando de $-\infty$ a $\infty$. Sua forma estrutural é dada por (2):

$$
y *=x_{i} \beta+\varepsilon_{i}
$$

Se houver apenas uma variável explicativa, a forma estrutural de $y *$ torna-se (3): 


$$
y *=\alpha+\beta x_{i}+\varepsilon_{i},
$$

Tem-se que na equação (3), $i$ se refere à observação e $\varepsilon$ a um erro aleatório. A variável latente $y *$ é dividida em $J$ categorias, conforme (4):

$$
y_{i}=k_{\text {se }} \pi_{k-1} \leq y * \leq \pi_{k} \text { para } k=1 \mathrm{a} J
$$

$\mathrm{Na}$ equação (4), os pontos de corte $\pi_{1} \mathrm{a} \pi_{\mathrm{I}-1}$ são estimados. Os autores Long e Freese (2006) assumem $\pi_{0}=-\infty$ e $\pi_{\mathrm{T}}=\infty$. De acordo com Boes e Winkelmann (2005), para as probabilidades serem bem definidas, além da equação (4), é preciso que $F(\infty)=1 \mathrm{e}$ $F(-\infty)=0$, em que F é uma distribuição logística. Segundo esses mesmos autores, $y$ * tem uma relação linear com fatores observáveis e não observáveis, em que os últimos têm uma função de distribuição específica $F(u)$ com média zero e variância constante.

A proxy da tolerância à corrupçáo, para este modelo, é a "corrup._" que mede a percepção dos indivíduos sobre "ser justificável aceitar suborno no exercício de suas funçōes", com 10 categorias, em que $J=1,2, \ldots ., 9,10$. A categoria (1) indica menos tolerância do individuo em relaçáo à corrupçáo, enquanto a categoria mais elevada (10) indica uma percepçâo mais tolerante à corrupção. Seguindo a ideia da variável latente $y *$, as categorias de resposta observadas estáo ligadas à variável latente pelo modelo de medição (5):

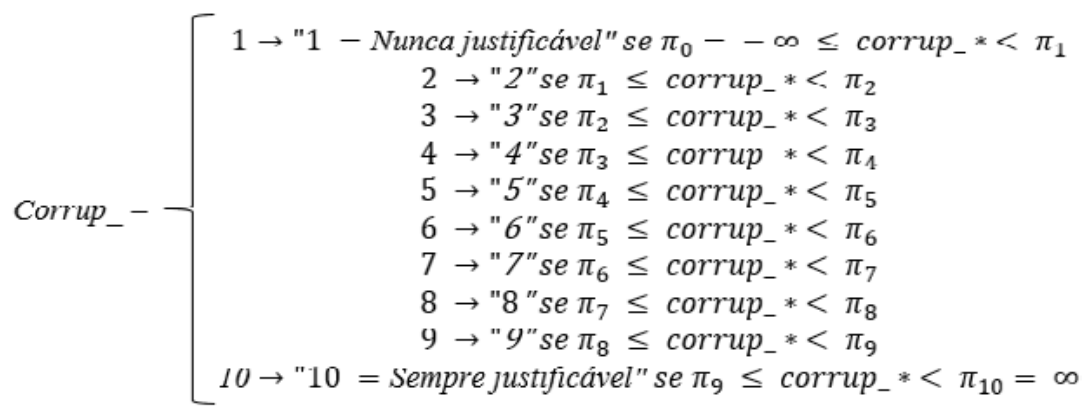

Neste sentido, quando variável latente cruza um ponto de corte (ou limite), a categoria observada passa a ser outra. Sendo assim, probabilidade de um resultado observado para um dado valor de $x$ é a área sob a curva entre um par de pontos de corte. Deste modo, a probabilidade de observar $y=k$ para valores dados de $x$, equivalentes à regiáo da distribuição onde $y$ * se encontra entre $\pi_{k-1}$ e $\pi_{k}$ é (6):

$$
\operatorname{Pr}(\mathrm{y}=\mathrm{k} \mid \mathrm{x})=\operatorname{Pr}\left(\pi_{\mathrm{k}-1} \leq \mathrm{y} *<\pi_{\mathrm{k}} \mid \mathrm{x}\right)
$$

Substituindo $x \beta+\varepsilon$ por $y^{*}$ e usando manipulaçôes algébricas chega-se à fórmula padrão para a probabilidade prevista no modelo de regressão logóstica ordenado (7):

$$
\operatorname{Pr}(\mathrm{y}=\mathrm{k} \mid \mathrm{x})=\mathrm{F}\left(\pi_{\mathrm{k}}-\mathrm{x} \beta\right)-\mathrm{F}\left(\pi_{\mathrm{k}-1}-x \beta\right)
$$


Para Boes e Winkelmann (2005), o foco principal da análise de dados deve ser colocado nas probabilidades de células condicionais. Isso foi expresso na equação (7). Segundo os autores, essa mesma equação representa uma função de probabilidade que possibilita a aplicação de métodos de máxima verossimilhança para uma amostra aleatória. $\mathrm{Na}$ mesma linha destes autores, Long e Freese (2006) demonstram que $F(-\infty-x \beta)=0$ e $F(\infty-x \beta)=1$, quando $y=1$ e $y=J$, respectivamente.

Salienta-se que os coeficientes são apresentados no formato de razão de chance (RC), ou seja, $\mathrm{e}^{\beta}$ ao invés de $\beta$. Os erros padrão e intervalos de confiança são igualmente transformados. Esta opção afeta a forma como os resultados são exibidos, não como eles são estimados. Além disso, esse tipo de apresentação facilita a interpretação das relaçóes entre a variável dependente e as variáveis explicativas. $\mathrm{O}$ valor da $\mathrm{RC}$ pode ser transformado em incremento percentual $((\mathrm{RC}-1) \times 100)$, e é a interpretação utilizada neste trabalho.

\section{Resultados e discussão}

A primeira parte refere-se aos resultados da Análise de Correspondência Múltipla. As variáveis foram separadas em quatro grupos, facilitando a análise visual dos gráficos de correspondência. Assim, é testada a associação da proxy para tolerência à corrupçáo em cada grupo. Buscou-se unir as variáveis com certa correlação entre si, de acordo com a literatura estudada e com a própria classificação sugerida pela WVS. A segunda parte destina-se aos resultados da regressão logística ordenada, cuja variável dependente é a proxy para tolerência à corrupção, medida a partir da percepção dos indivíduos sobre suborno.

É importante destacar que esses resultados vão ao encontro das abordagens teórica e empírica, considerando que a dimensão "corrupção" adaotada aqui está relacionada à forma cultural, alinhada a um juízo de desonestidade (campo simbólico), conforme Figuleira (2008). Além disso, pode-se considerar o recorte apresentado por Johnston (1982), em que essa dimensão de corrupção poder estar relacionada à interação do governo com o público, dado que optou-se aqui por uma variável relacionada à percepção das pessoas sobre a prática de recebimento de suborno no trabalho.

\subsection{Associação múltipla: resultados da ACM}

O primeiro grupo trata de variáveis sociodemográficas (gênero, ocupação, educação e renda). Os pares dessas variáveis se mostram associados estatisticamente a um nível de $5 \%$ de significância. As dimensóes 1 e 2 da análise explicam, respectivamente, 19,6\% e $15,4 \%$ da relação entre as variáveis do grupo. O mapa perceptual da associação múltipla está representado pela Figura 1.

E possível perceber uma associação entre dois grupos distintos de categorias. No lado esquerdo tem-se "homem" e os níveis de percepção relativamente mais tolerantes à corrupção. Essa relação vai ao encontro de Swamy et al. (1999), que acreditam ser plausível a ideia de haver um diferencial de gênero na aceitação da corrupção, uma vez que as mulheres estão envolvidas em menos casos de suborno. Nesse sentido, Lambsdorff (2006), ao destacar a questão do gênero como uma das causas da corrupção, acredita que 
os resultados encontrados até então sugerem que políticas destinadas a aumentar o papel das mulheres no mercado de trabalho poderiam ajudar na redução dos níveis de corrupção. Ainda sobre a Figura 1, no lado direito percebe-se uma associação entre ser mulher, baixas escolaridade e renda, desempregado e com percepção menos tolerante à corrupção.

Figura 1 - Mapa de correspondência - corrupção e dimensão sociodemográfica

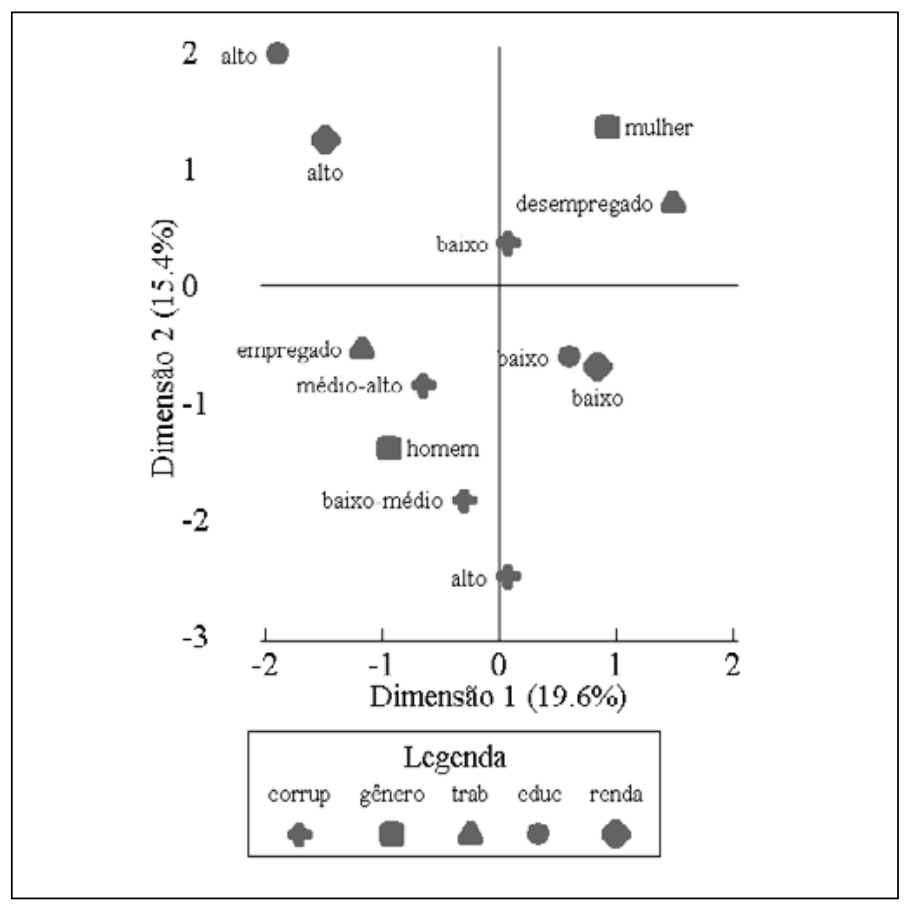

Fonte: Elaboração própria a partir da WVS. (Software: Stata 12)

O segundo grupo contempla a relaçáo entre a dimensão "corrupção" e a dimensão "religiáo". Ele é composto por variáveis sobre denominaçōes religiosas (relig) e sobre a confiança na igreja (conf_igrej). As dimensóes 1 e 2 explicam, respectivamente, $15 \%$ e $11,6 \%$ da inércia total da análise de correspondência. As associaçóes entre as variáveis foram estatisticamente significantes ao nível de 5\% (Figura 2).

A análise gráfica sugere que ser "protestante" está associado a um nível "baixo" de tolerância à corrupçáo. Este resultado corrobora com os estudos de La Porta et al. (1997), Treisman (2000), Power e González (2003) e Lambsdorff (2006), autores que associam a presença da tradição protestante a níveis baixos de corrupção. A tradição "muçulmana" também se mostrou distante dos níveis mais elevados de aceitação da corrupção, enquanto indivíduos identificados com a religião "católica" podem considerar relativamente mais justificável a corrupção. Estes resultados podem ser analisado à luz das contribuiçóes de La Porta et al. (1997/1999), que associam a tradição muçulmana e a católica a níveis mais elevados de corrupçáo por acreditarem que elas, sendo mais hierarquizadas, prejudicam a participação cívica dos cidadáos, ocasionando o aumento dos níveis de corrupção na sociedade. 
Figura 2 - Mapa de correspondência - corrupção e dimensão religiosa

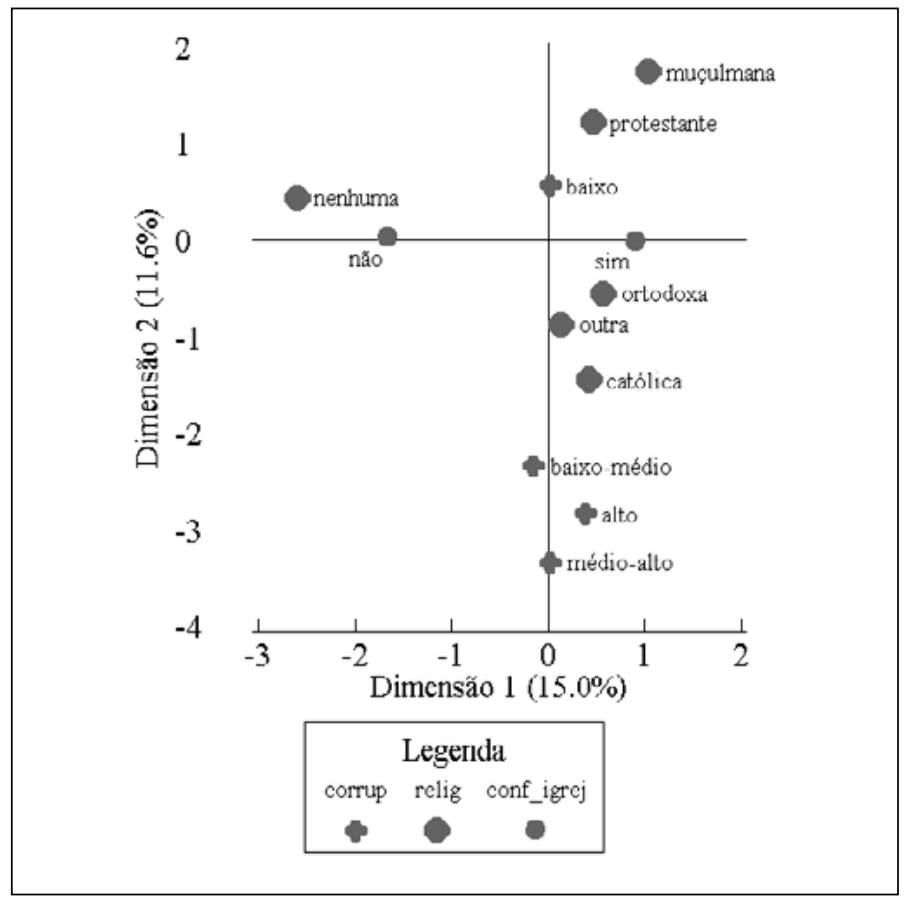

Fonte: Elaboração própria a partir da WVS. (Software: Stata 12)

Power e González (2003) argumentam que a associação negativa entre corrupção e protestantismo pode estar relacionada ao impacto cultural prolongado da Reforma Protestante, do século XVI. Os resultados de Barbosa (2012) indicam alguma relação entre tradiçóes católica e muçulmana e corrupção. Porém, para Shabbir e Anwar (2007), ao estudarem os países em desenvolvimento, a religião demonstrou uma associação muito fraca com a corrupção, sendo incapaz de diminuir os níveis desse fenômeno. Deste modo, eles concluíram que é necessária uma reavaliação deste esse fato, principalmente pelos cidadãos e líderes religiosos.

O terceiro grupo destina-se à análise da dimensão "corrupção" e a dimensão "renda", sendo composto por variáveis sobre ocupação (trab), grupo de renda, igualdade de renda (rend_iguais) e responsabilidade sobre a própria renda e sustento (rend_prop). A Figura 3 traz o mapa de correspondência. No lado esquerdo, sugere-se uma associação entre indivíduos na categoria de alta renda; aqueles que têm uma percepção desfavorável a maior igualdade de renda; aqueles que acreditam que o indivíduo deve ser responsável pela busca da renda; e o tipo de indivíduo do tipo "médio-alto" de tolerância à corrupção. Para RoseAckerman (1997), a corrupção tende a favorecer as pessoas que já detém certo nível de renda, ou seja, pessoas que já tem uma estabilidade financeira. Deste modo, a corrupçáo aumenta a renda de quem já tem, podendo ampliar o nível de desigualdade de renda entre os indivíduos. 
Figura 3 - Mapa de correspondência - corrupção e dimensão renda

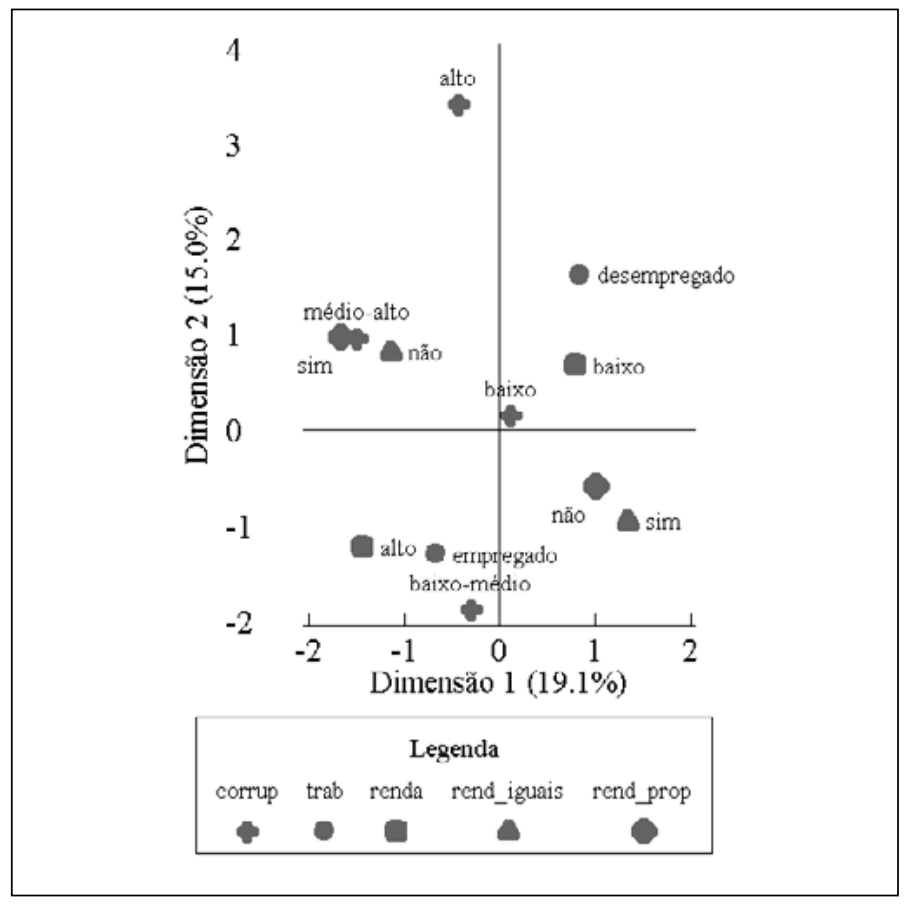

Fonte: Elaboração própria a partir da WVS. (Software: Stata 12)

Por fim, o quarto grupo se dedica à análise da relação entre a dimensão "corrupção" e a dimensão institucional ligada à confiança e à democracia. Compóem o grupo a proxy de tolerância à corrupção, as variáveis de confiança nas pessoas, no governo, na imprensa e no sistema de justiça, além da "preferência por democracia". O mapa de correspondência está expresso pela Figura 4.

Destaca-se uma associação entre o nível "alto" e "médio-alto" de percepção mais tolerante à corrupção e a percepção negativa sobre a democracia como um bom sistema político. Essa associação sugere que corrupção e democracia estão em dimensóes relativamente opostas. Para Power e González (2003), o nível de corrupção tende a diminuir na presença de uma democracia forte e eficiente. Para Tanzi (1998), a corrupçáo retarda ou até mesmo bloqueia o movimento em direção a uma democracia sólida e eficiente. 
Figura 4 - Mapa de correspondência - corrupção e dimensão confiança

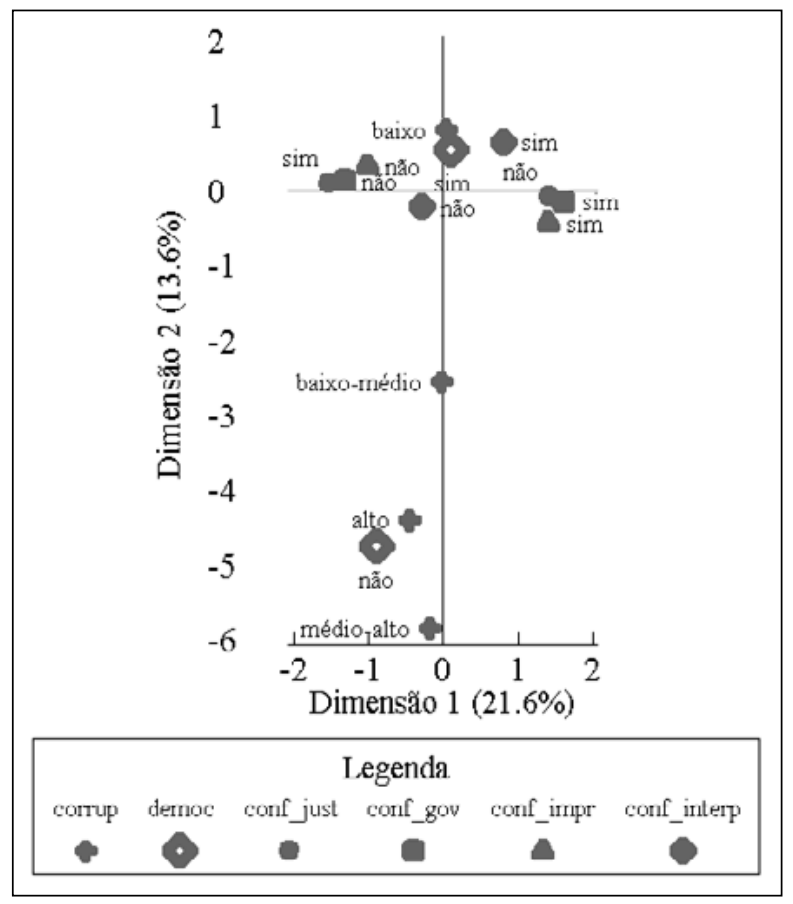

Fonte: Elaboração própria a partir da WVS. (Software: Stata 12)

As categorias de respostas sobre confiança na imprensa, no governo, no sistema de justiça e a confiança interpessoal se encontram próximas, mas com associação relativamente distante das categorias mais elevadas de tolerância à corrupção. De qualquer forma, a literatura aponta algumas relaçóes. Para Mauro (1995), países onde o sistema judiciário é ineficiente e não confiável, tendem a ser mais corruptos. Uma imprensa livre é vista como eficaz para a diminuição dos níveis de corrupção (BRUNETTI e WEDER, 2003; SHABBIR e ANWAR, 2007; BARBOSA, 2012). Para Tanzi (1998), atos corruptos reduzem ou distorcem o papel importante do governo em áreas como a execução de contratos, proteção dos direitos de propriedade, imposição de controles regulatórios e intervençôes necessárias para corrigir as falhas de mercado. No que tange a confiança interpessoal, Barbosa (2012) sugere que maior nível dessa variável tende a diminuir os casos de corrupçáo.

\subsection{Resultados do modelo LOGIT ordenado}

Aqui se pretende analisar os efeitos das variáveis socioinstitucionais, discutidas no subtópico anterior, sobre a medida de tolerância à corrupção. A variável dependente de código "corrup_" está dividida em 10 categorias, de acordo com a distribuiçâo original da WVS. Os resultados do modelo de regressão logística ordenada estão apresentados na Tabela 5 . 
Tabela 5 - Resultados do modelo LOGIT ordenado

\begin{tabular}{|c|c|c|c|}
\hline Corrup_ & Razão de chance & Desvio Padrão & \\
\hline Gênero & $1,1295^{* * *}$ & 0,0252274 & Wald Chi2 (15): 213,77 \\
\hline Trab & $1,1054^{* * *}$ & 0,0364163 & Prob> Chi2: 0,0000 \\
\hline Educ & $0,84570^{* * *}$ & 0,0419888 & Pseduo R²: 0,0061 \\
\hline Renda & $1,1510^{* * *}$ & 0,0530102 & Observaçóes: 148.244 \\
\hline Rend_iguais & 1,0305 & 0,0414823 & \\
\hline Rend_prop & $0,9061^{* *}$ & 0,0488335 & (Des. Pad.) \\
\hline Democ & $1,7184^{* * *}$ & 0,1192376 & Corte $1: 3,131873(2,096377)$ \\
\hline Conf_just & $0,92522^{* *}$ & 0,0375532 & Corte $2: 3,718735(2,096377)$ \\
\hline Conf_gov & 1,0065 & 0,0463157 & Corte 3: 4,167888 $(2,089571)$ \\
\hline Conf_impr & $0,8836^{* *}$ & 0,0430066 & Corte 4: 4,494757 (2,091919) \\
\hline Conf_interp & 0,9667 & 0,0571261 & Corte 5: 5,047553 $(2,089847)$ \\
\hline Conf_igrej & 0,9390 & 0,053918 & Corte 6: 5,437308 (2,090476) \\
\hline \multirow[t]{3}{*}{ Relig } & 1,0222 & 0,0207003 & Corte 7: 5,794907 $(2,091777)$ \\
\hline & & & Corte 8: 6,198613 $(2,096205)$ \\
\hline & & & Corte 9: 6,569198 $(2,104049)$ \\
\hline
\end{tabular}

Nota: Erro padrão ajustado para 89 clusters (uso da variável S003 - países). Peso S018 extraído da WVS. Dummies de tempo (onda) foram consideradas. (Software: Stata 12 ). ${ }^{* *} 1 \%$, ${ }^{* *} 5 \%$ de significância.

Fonte: Elaboração própria.

Os resultados indicam que a variável dependente, de fato, apresenta categorias ordenadas, conforme valores crescentes dos cortes de 1 a 9. Já sobre os coeficientes das variáveis explicativas, expressos em razão de chance, tem-se que a maior parte revelou-se significativa. Primeiro, o fato de o indivíduo ser homem pode aumentar as chances de este ser mais tolerante à corrupção. Isso fortalece o argumento de Swamy et al. (1999), a respeito da existência de um diferencial de gênero, tendo as mulheres como menos tolerantes à corrupção.

Em relação ao nível de renda, se estiver em categoria do tipo "alta”, pode aumentar a probabilidade de o indivíduo ser do tipo mais tolerante à corrupção. Esse resultado pode ser analisado à luz do trabalho de Rose-Ackerman (1997), em que a prática de atos corruptos tende a beneficiar os indivíduos que já possuem um determinado nível de renda. Sobre a variável que indica preferência por igualdade de renda, seu coeficiente não apresentou significância estatística. Já sobre a percepção da "responsabilidade pela própria renda", o resultado sugere uma redução das chances do indivíduo ser do tipo mais favorável à corrupção.

Sobre educação e emprego, um nível elevado de escolaridade pode reduzir as chances de o indivíduo ter uma percepção mais favorável à corrupção; e estar empregado também pode aumentar essas chances. Não há um consenso exato a respeito da associação entre educação e corrupção. Na visão de Mauro (1995), os governos mais corruptos e instáveis tendem a investir menos em educação, uma vez que não há muitas possibilidades para realização de atos corruptos neste setor, diferente de outros como o da saúde. De acordo com os resultados de Shabbir e Anwar (2007), a associação entre corrupção e educação se 
mostrou positiva. Os autores chegam ao consenso de que, nos países em desenvolvimento, a corrupção tende a aumentar quando o nível educacional aumenta.

A análise ainda expõe um resultado importante e significativo ao associar tolerância à corrupção e democracia. As chances do indivíduo ser mais tolerante à corrupção podem ser maiores quando este tem uma percepção negativa sobre a democracia como sistema político. Esse resultado vai ao encontro do que a literatura indica (TANZI, 1998; POWER E GONZÁLEZ, 2003; LAMBSDORFF, 2006; BARBOSA, 2012).

No que tange à confiança dos indivíduos, confiar no sistema de justiça pode reduzir a probabilidade de estes serem mais tolerantes à corrupção. Segundo Mauro (1995), os países onde o sistema judiciário é confiável e eficiente, tendem a ser menos corruptos. Já sobre ser do tipo que confia mais imprensa, pode haver uma redução das chances do indivíduo ser mais favorável à corrupção. Essa correlação negativa entre imprensa livre e corrupção é vista pela literatura como instrumento potencialmente eficaz para reduzir os níveis desse fenômeno (BRUNETTI e WEDER, 2003; LAMBSDORFF, 2006; SHABBIR e ANWAR, 2007; BARBOSA, 2012). Quanto à confiança no governo e a confiança interpessoal, os coeficientes não se mostraram significativos. Além destas, as variáveis da dimensão "religião" também não apresentaram coeficientes estatisticamente significativos.

A partir desse conjunto de resultados, tanto da análise multivariada quanto do modelo de regressão logística ordenada, os quais se mostraram complementares na identificação das associações entre um grupo de variáveis socioinstitucionais e uma medida de tolerância à corrupção, fica evidente a importância de pesquisas empíricas, no nível dos indivíduos, para colaborar com as discussóes teóricas dos diversos campos do conhecimento.

\section{Consideraçóes finais}

Entender a complexidade de conceitos, causas e consequências da corrupção é uma atividade relativamente recente e tem se tornado mais frequente nas últimas décadas. Um dos caminhos pode ser a avaliação e acompanhamento do grau de tolerância dos indivíduos à corrupção e, além disso, dos fatores que podem afetar essa percepção. É comum relacionar esse fenômeno à depravação, desmoralização e suborno, quase sempre associando a corrupção a um ato ilegal e ao poder político ou econômico de determinados grupos da sociedade. Apesar de o senso comum conectar corrupção aos agentes da esfera pública (policiais e fiscais, por exemplo), deve-se reforçar que esse fenômeno está presente também no campo privado.

As pesquisas empíricas sobre corrupção são escassas, tendo em vista a complexidade teórica do tema, que pode envolver variadas áreas e linhas de pesquisa com abordagens culturais, sociais, políticas, econômicas ou institucionais. Assim, o objetivo deste trabalho foi analisar, no nível dos indivíduos, as conexôes entre tolerância à corrupção e variáveis socioinstitucionais, tais como gênero, educação, religião e confiança, a partir de método de análise multivariada e de um modelo de regressão logística ordenada.

A variável categórica que identifica a percepção dos indivíduos sobre a aceitação da prática de suborno foi escolhida como proxy para tolerância à corrupção, extraída da Pesquisa Mundial de Valores (WVS). É importante mencionar aqui que mesmo tomando a 
definição da corrupção direcionada a uma forma puramente econômica (suborno), buscouse associação com os possíveis determinantes sociais, institucionais e outras características dos indivíduos.

Os métodos empregados foram escolhidos a partir da estrutura do conjunto de dados, exclusivamente categóricos, e os resultados podem sugerir as seguintes conexóes: há indícios de um diferencial de gênero quando relacionado com níveis de tolerância à corrupção, dando indicativos de que homens (em relação às mulheres) poderiam aceitar mais facilmente o suborno; há evidências de que um sistema político mais democrático tende a diminuir os níveis de tolerância à corrupção; uma imprensa mais livre e ativa tende a ser benéfica para a redução da tolerância à corrupção e os resultados sugerem que indivíduos que confiam na imprensa tendem a ser do tipo menos favorável à corrupção; um sistema de justiça mais confiável tende a contribuir para a queda dos casos de corrupçáo, tendo o resultado apontado uma relação direta entre mais confiança na justiça e menos tolerância à corrupção; níveis altos de renda dáo indícios de uma associação positiva a corrução e os resultados sugerem que os indivíduos com nível alto de renda tem uma percepção mais tolerantes à corrupção; há sinais da existência de uma maior desigualdade de renda na presença de corrupção e as análises demonstraram haver sinais de que os indivíduos contrários a uma igualdade de renda podem ser do tipo mais tolerante ao ato corrupto; e pode haver uma relação inversa entre escolaridade e corrupção, ou seja, indivíduos com maior nível alto de educação tende a diminuir a propensão a ser do tipo mais tolerante à corrupção.

Embora nas últimas quatro décadas os estudos sobre a corrupção tenham adquirido certa consistência e frequência, ainda é preciso avançar empiricamente nesse tema. A revisão das vertentes de pensamento sobre o tema revela grande diversidade de enfoques quando se trata de analisar suas causas e consequências. Dependendo do investigador, são discutidos pontos relativos à natureza humana ou questôes de ordem econômica, política, social e cultural. As propostas de solução também são variadas, passando de medidas mais passivas até açôes mais sistemáticas.

No que tange a medida de tolerância à corrupção por parte dos indivíduos, o fato é que uma série de fatores comumente pensados para causar corrupção podem influenciar essa tolerância. Sugere-se cautela nas análises com medidas de percepção da corrupção, mas estudos nessa linha são uma parte importante para compreensão da atitude das pessoas em relação aos sistemas e à confiança nas instituições. Sabe-se que essa confiança pode ser um determinante das decisóes de investimento, da participação política, como o voto, e de outros comportamentos com reais efeitos sobre outras dimensóes sociais e econômicas.

A presente pesquisa sugere que, ao se considerar as causas multidimensionais (valores, categorias de renda e outras instituiçôes) da corrupção como uma das possíveis abordagens para se estudar o fenômeno, é possível compreender e avaliar empiricamente as relaçóes no nível individual que podem modificar o comportamento dos agentes, em termos de tolerância da corrupção, colaborando para futuras pesquisas sobre o tema. Por fim, ainda para futuras pesquisas, deve-se investigar as possíveis relações de causalidade reversa envolvendo a tolerância à corrupção e outras dimensóes dos campos social, econômico e institucional. 


\section{Referências}

ABRAMO, C. W. Percepçóes pantanosas: a dificuldade de medir a corrupção. Novos estudos - CEBRAP, n.73, nov. pp.33-37, 2005.

ABRAMO, C. W. Relação entre Índices de Percepção da Corrupção e outros Indicadores em 11 países da América Latina. Cadernos Adenauer, (10). São Paulo: Fundação Konrad Adenauer, 2000.

ADES, A.; DI TELLA, R. The Causes and Consequences of Corruption: A Review of Recent Empirical Contributions. In: Harris-White, B. White, G. (eds). Liberalization and the new corruption. IDS Working Papers, 1996.

AITCHISON, J.; SILVEY, S. D. The Generalization of Probit Analysis to the Case of Multiple Responses. Biometrika, vol.44, pp.131-140, 1957.

BANCO MUNDIAL. World Development Report 1997, Washington D.C.: World Bank, 1997.

BARBOSA, T. A. Da influência dos valores culturais na percepçáo e prática da corrupçáo: de perspectivas teóricas a evidências empíricas. Dissertação (Mestrado em Ciência Política) - Instituto de Ciência Política, Universidade de Brasília, Brasília, 2012.

BOES, S.; WINKELMANN, R. Ordered Response Models. Working Paper No 0507, Socioeconomic Institute University of Zurich, 2005.

BRUNETTI, A.; WEDER, B. A Free Press is Bad News for Corruption. Journal of Public Economics, Volume 87, Issues 7-8, Pages 1801-1824, 2003.

BUCHANAN, J. M. Rent seeking and profit seeking. In: Buchanan, J.; Tollison, R.; Tullock, G. (Ed.). Toward a theory of the rent-seeking society. College Station, Texas: Texas A\&M University Press, pp. 3-15, 1980.

CAMERON, A. C., TRIVEDI, P. K. Microeconometrics: Methods and Applications. New York: Cambridge University Press, 2005.

DE LA CROIX, D.; DELAVALLAD, C. Growth, public investment and corruption with failing institutions. Economic Governance, v10, pp.187-219, 2007.

DOLLAR, D.; FISMAN, R.; GATTI, R. Are women really the 'fairer' sex? Corruption and women in government. Journal of Economic Behavior and Organization, v46, pp.423-429, 2001.

DONCHEV, Dilyan; UJHELYI, Gergely. What Do Corruption Indices Measure? Available at SSRN: http://ssrn.com/abstract=1124066 or http://dx.doi.org/10.2139/ ssrn.1124066, 2009. 
DONFOUET, H. P. P.; JEANTY, P. W.; MALIN, E. Analysing spatial spillovers in corruption: A dynamic spatial panel data approach. Regional Science, May. Volume 97, Supplement 1, 2018.

FÁVERO, L. P. L.; BELFIORE, P. Análise de Dados: Técnicas Multivariadas

Exploratórias com SPSS e Stata. Rio de Janeiro: Elsevier, 2015.

FÁVERO, L. P.; BELFIORE, P.; TAKAMATSU, R. T.; SUZART, J. A. S. Métodos quantitativos com Stata. Rio de Janeiro: Elsevier, 2014.

FILGUEIRAS, F. Corrupção, Democracia e Legitimidade. Belo Horizonte: Editora UFMG, 2008.

FISMAN, R.; GATTI, R. Decentralization and corruption: evidence across countries. Journal of Public Economics, n. 83, p. 325-345, 2002.

GARCIA, R. L. A Economia da Corrupção - Teoria e Evidências - Uma aplicaçáo ao Setor de Obras Rodoviárias no Rio Grande do Sul. Tese (Doutorado em Economia) Faculdade de Ciências Econômicas, Universidade Federal do Rio Grande do Sul, Porto Alegre, 2003.

GLYNN, P.; KOBRIN, S. J.; NAIM, M. The globalization of corruption. Institute for International Economics, Disponível em https://piie.com/publications/chapters_ preview/12/1iie2334.pdf, 1997.

GOEL R. K.; NELSON, M. A. Are corrupt acts contagious? Evidence from the United States. Journal of Policy Modeling, pp.839-850, 2007.

GOWER, J. C. Fisher's optimal scores and multiple correspondence analysis. Biometrics 46: 947-961, 1990.

GOWER, J. C., AND D. J. HAND. Biplots. London: Chapman \& Hall, 1996.

GREENACRE, M. J. Multiple Correspondence Analysis and Related Methods. Boca Raton, FL: Chapman \& Hal, 2006.

GUPTA, S.; DEMELLO, L.; SHARAN, R. Corruption and military spending. European Journal of Political Economy, v17: 749-777, 2001.

HODGSON, G. M.; JIANG, S. The Economics of Corruption and the Corruption of Economics: An Institutionalist Perspective. Journal of Economic Issues. v. XLI, n.4, 2007.

HUNTINGTON, S. Political order in changing societies. New Haven, 1968. 
HUDSON, J.; JONES, P. Corruption and military expenditure: At 'no cost to the king'. Defence and Peace Economics, v19: 387-403, 2008.

INGLEHART, R. World Values Surveys and European Values Surveys. 1981-194, 1990-1993, and 1995-1997 (Databank and Codebook). Study n.2790. Michigan: Ann Arbor-Inter-University Consortium for Political and Social Research, 2000.

LA PORTA , R.; LOPEZ-DE-SILANES; SHLEIFER, A.; VISHNY, R. W. The Quality of Government. Oxford University Press, 1999.

LA PORTA , R.; LOPEZ-DE-SILANES; SHLEIFER, A.; VISHNY, R. W. Trust in Large Organizations. American Economic Review, Nashville, v. 87, n. 2, p. 333-338, 1997.

LAMBSDORFF, J. G. Causes and Consequences of Corruption: What Do We Know from a Cross-Section of Countries? In: International Handbook on The Economics of Corruption. Ed. Susan Rose-Ackerman. Edward Elgar Publishing, 2006.

LEFF, N. H. Economic Development through Bureaucratic Corruption. American Behavioral Scientist, p.8-14, 1964.

LONG, J. S.; FREESE, J. Regression Models for Categorical Dependent Variables Using Stata, 2. ed. Stata Press, 2006.

JOHNSTON, M. Political corruption and public police in America. Monterey. Brooks/Cole, 1982.

MBAKU, J. M. Corruption and rent-seeking. In: The political dimension of economic growth. Palgrave Macmillan, London, p. 193-211, 1998.

MAURO, P. Corruption and Growth. Quarterly Journal of Economics. v.110, p. 681$712,1995$.

MAURO, P. The Effects of Corruption on Growth, Investment, and Government Expenditure. IMF Working Paper WP/96/98, Washington: International Monetary Fund, 1996.

ORTEGA, D. L.; FLORAX, R. J. G. M; DELBECQ, B. A. Primary determinants and the spatial distribution of corruption. The Empirical Economics Letters, v10, pp.1123$1130,2011$.

PARK, H. Determinants of corruption: A cross-national analysis. The Multinational Business Review, v11, pp. 29-48, 2003.

POWER, T. J.; GONZALES, J. Cultura política, capital social e percepçóes sobre corrupção: uma investigação quantitativa em nível mundial. Revista de Sociologia e Política. Curitiba: UFPR, n. 21, 2003. 
ROWLEY, C. K. Rent-seeking versus Directly unproductive profit-seeking activities. In: Tullock, G. The political economy of the educational process. Boston: Kluwer, 1988.

ROSE-ACKERMAN, S. Corruption: A Study in Political Economy, New York, NY: Academic Press, 1978.

ROSE-ACKERMAN, S. The Political Economy of Corruption, in Kimberly Ann Elliott, ed., Corruption and the Global Economy, Washington: DC: Institute for International Economics, pp. 31-60, 1997.

SHABBIR, G.; ANWAR, M. Determinants of Corruption in Countries. The Pakistan Development Review, vol. 46: 4, part II, p. 751-764, 2007.

SWAMY, A.; LEE, Y. KNACK, S. \& AZFAR, O. Gender and Corruption. Working Paper n. 22. College Park : IRIS Center University of Maryland, 1999.

SILVA, M. F. G. A economia política da corrupçáo. FGV/EESP-Escola de Economia de São Paulo, Fundação Getúlio Vargas - FGV, 1996.

SILVA, M. F. G. A economia política da corrupçáo no Brasil. São Paulo: Editora SENAC São Paulo, 2001.

SOUZA, A. C.; BASTOS, R. R.; VIEIRA, M. T. Análise de correspondência simples e múltipla para dados amostrais complexos. In: Simpósio Nacional De Probabilidade e Estatística, 19. São Paulo: SINAP, 2010.

TANZI, V. Corruption, Around the World: Causes, Consequences, Scope, and Cures. IMF Staff Paper, v.45, n.4, p.559-59, 1998.

TREISMAN, D. The causes of corruption: a cross-national study. Journal of Public Economics 76, pp. 399-457, 2000.

WVS. World Value Survey 1981-2014 Longitudinal Aggregate. World Values Survey Association (www.worldvaluessurvey.org). Aggregate File Producer: JDSystems Data Archive, Madrid, Spain.

\section{Anexos}

Tabela A1 - Países participantes

\begin{tabular}{c|c|c|c}
\hline País / Região & País / Região & & \\
\hline África do Sul & Croácia & Israel & Quirguistão \\
\hline Albânia & Egito & Itália & Rep. Dominicana \\
\hline Alemanha & El Salvador & Japão & República Tcheca \\
\hline Andorra & Equador & Jordânia & Romênia \\
\hline
\end{tabular}




\begin{tabular}{c|c|c|c}
\hline Arábia Saudita & Eslováquia & Kuwait & Ruanda \\
\hline Argélia & Eslovênia & Letônia & Rússia \\
\hline Argentina & Espanha & Líbano & Sérvia \\
\hline Armênia & Estados Unidos & Líbia & Sérvia e Montenegro \\
\hline Austrália & Estônia & Lituânia & Suécia \\
\hline Azerbaijáo & Etiópia & Macedônia & Suíça \\
\hline Bangladesh & Filipinas & Malásia & Tailândia \\
\hline Bahrein & Finlândia & Mali & Taiwan \\
\hline Belarus & França & Marrocos & Tanzânia \\
\hline Bósnia & Gana & México & Trinidade e Tobago \\
\hline Brasil & Geórgia & Moldávia & Tunísia \\
\hline Bulgária & Graa-Bretanha & Montenegro & Turquia \\
\hline Burquina Faso & Guatemala & Nigéria & Ucrânia \\
\hline Canadá & Holanda & Noruega & Uganda \\
\hline Cazaquistáo & Hong Kong & Nova Zelândia & Uruguai \\
\hline Chile & Hungria & Palestina & Uzbequistáo \\
\hline China & Iêmen & Paquistấo & Venezuela \\
\hline Chipre & Índia & Peru & Vietná \\
\hline Cingapura & Indonésia & Polônia & Zâmbia \\
\hline Colômbia & Irã & Porto Rico & Zimbábue \\
\hline Coréia do Sul & Iraque & Qatar & \\
\hline
\end{tabular}

Fonte: Elaboração própria a partir de dados da WVS.

Tabela A2 - Análise de correlação entre as variáveis explicativas

\begin{tabular}{c|c|c|c|c|c|c|c|c|c|c|c|c|c}
\hline & Gên & Tra & Edu & Ren & Re_i & Re_p & Rel & Dem & C_ju & C_go & C_im & C_in & C_ig \\
\hline Gênero & 1,0000 & & & & & & & & & & & & \\
\hline Trab & 0,1974 & 1,0000 & & & & & & & & & & & \\
\hline Educ & 0,0166 & 0,1279 & 1,0000 & & & & & & & & & & \\
\hline Renda & 0,0213 & 0,1298 & 0,2021 & 1,0000 & & & & & & & & & \\
\hline $\begin{array}{c}\text { Rend_ } \\
\text { iguais }\end{array}$ & 0,0266 & 0,0379 & 0,0528 & 0,1041 & 1,0000 & & & & & & & & \\
\hline Rend_prop & $-0,0218$ & $-0,0352$ & $-0,0391$ & $-0,1093$ & $-0,2124$ & 1,0000 & & & & & & & \\
\hline Relig & 0,0471 & 0,0394 & 0,0396 & 0,0031 & $-0,0195$ & 0,0541 & 1,0000 & & & & & & \\
\hline Democ & $-0,0140$ & $-0,0140$ & $-0,0512$ & $-0,0207$ & $-0,0078$ & 0,0055 & 0,0364 & 1,0000 & & & & & \\
\hline Conf_just & $-0,0059$ & 0,0068 & 0,0016 & 0,0555 & $-0,0001$ & $-0,0394$ & 0,0079 & $-0,0613$ & 1,0000 & & & & \\
\hline Conf_gov & $-0,0017$ & $-0,0052$ & $-0,0192$ & 0,0347 & 0,0146 & $-0,0345$ & $-0,0147$ & $-0,0641$ & 0,4332 & 1,0000 & & & \\
\hline Conf_impr & $-0,0100$ & 0,0101 & 0,0321 & $-0,0190$ & $-0,0075$ & $-0,0061$ & $-0,0052$ & 0,0339 & $-0,2847$ & $-0,2769$ & 1,0000 & & \\
\hline $\begin{array}{c}\text { Conf_ } \\
\text { interp }\end{array}$ & 0,0074 & 0,0531 & 0,1092 & 0,0716 & $-0,0218$ & $-0,0562$ & 0,0370 & $-0,0312$ & 0,1237 & 0,0819 & $-0,0396$ & 1,0000 & \\
\hline & & & & & & & & & & & & & \\
\hline Conf_igrej & 0,0549 & 0,0599 & 0,0601 & 0,0173 & $-0,0334$ & $-0,0038$ & 0,2446 & 0,0217 & $-0,1176$ & $-0,1676$ & 0,1426 & 0,0338 & 1,0000 \\
\hline
\end{tabular}

Nota: Uso do Software Stata 12.

Fonte: Elaboração própria a partir dos dados da WVS. 